\title{
Analysis of the Relationship between Culture, Economy and Politics
}

\author{
Fu-Jiang SUN ${ }^{1, a^{*}}$ \\ ${ }^{1}$ Department of Public Administration, University of International Relations, Beijing 100091, China \\ asfj.006@163.com
}

Keywords: Culture, economy, politics, values, social consciousness, morality

\begin{abstract}
Culture refers to the consciousness about life and social relations in economic and political activities in a society, including values, social consciousness and morality. Economic and political practices are the basis and container of culture, while thoughts about and understanding of economic and political practices are the main content of culture. It is difficult to build a culture in isolation of social reality. Culture has its own particularity and will evolve with economic and political practices.
\end{abstract}

\section{Introduction}

What is culture? Many different answers can be found in existing literature. Some scholars believe that culture, relative to tangible things, is invisible and manifestation or products of human mind, including but not limited to thought, customs, ethics and knowledge [1]. Some hold that everything other than materials is culture. In other words, any existence with human or social imprints is culture [2]. Others define "culture" as the sum of material wealth and spiritual wealth created by human beings [3]. Shuming Liang believes that culture is everything human existence depends on [4-5].

As for the origin of culture, some people think that culture is a mysterious existence, invisible but powerful and omnipresent [6]. Some argue that culture is an external existence to human beings and society and exists prior to them [7]. Pure cultural researchers believe that Confucianism is a product of Chinese people's mindset and should be viewed as the only Chinese culture. They also argue that Confucius practices were carried forward by Confucius, Mencius, Xunzi, Zhongshu Dong, Yi Cheng, Hao Cheng, Xi Zhu, Jiuyuan Lu, Yangming Wang and other famous Confucianism scholars [8]. Others argue that culture is created by scholars who shut themselves up in their rooms [9].

This paper attempts to answer these questions on the basis of existing cultural research results [1-11].

\section{What is Culture?}

The broad and widely disputed definitions of culture as mentioned in the introduction may be a result of inconsistent definitions of the referent of culture. Under the above definitions, the scope of culture covers either the full consciousness of mankind or labor products of man. Based on these definitions, culture is almost equal to everything related to life and social life, including science, language, arts, social systems, laws, policies, management functions and other factors. Science, languages and arts are also conscious activities of mankind, but consciousness is not equal to culture. Science is activity encompassing the study of the natural world and the development of skills to transform the natural world. Language is a method used by human beings to express their mind and is the carrier of culture but not the culture itself. Art shows people's understanding of life and social relations but not culture itself. There are special fields of study for science, language and arts which, although closely related to culture, should not be included in the scope of culture. As for social systems, laws, policies and administrative functions, they are in the realm of politics. They certainly embody and restrict culture but, like economy, are not within the scope of culture.

Activities of human beings and society do reflect culture which in turn affects them but they are not culture itself in the same manner as we don't encompass everything in the definition of economy or politics. Although culture embodies and affects all social activities, not all social activities are culture. 
All colors of television are combination of red, green and blue but we won't say that all colors are red, blue or green. Culture is a major activity of human beings and society. It can only be explained in the context of social activities of human beings which give rises to culture. Of course, this is different with the color example. Red, blue or green in itself is a color. But to become an element of human and social activities, culture must be combined with social and political activities. Without this kind of combination, culture won't exist.

This paper argues that culture is a concentrated expression of human consciousness, but not all consciousness, only the part related to life and social relations. Culture should not encompass all human consciousness or everything with the imprint of human consciousness. Consciousness related to life and social relations mainly includes values, social consciousness and morality.

Values are beliefs of people about the purpose of life, life attitude and whether their own behavior and others' behavior is good or bad. Values can be divided into social values and personal values. Any person living in reality, in the process of survival and development, will inevitably, consciously or otherwise, ask himself or herself the following questions: "Who am I?" "What's my social status?" and "What should I do?" Behind questions such as "Who am I?" and "What should I do?" are more questions: "What's the purpose of my life?" "What is the meaning behind my action?" "How to maximize the value of my action?", etc. These questions will accompany everyone throughout his/her whole life, and answers to these questions vary by era, country and person. Despite the diversity of answers, these questions concerning values of life are omnipresent and must be answered. Otherwise, people will be lost. Individuals form personal values based on their thoughts about their own existence, needs, interests, social relations and other factors, while social values are beliefs created under certain historical conditions to guide the majority of members of a society. Social values not only are the collection of personal values within the society but also serve as wind vanes for personal values. Social values are general principles, while personal values are more specific and practical and directly restrict individuals' mindset and behavior. In addition to difference in physical features, age, gender and skills, the most important difference between individuals is about values. Values are the core and basic content of culture and are further embodied in social consciousness and morality.

Social consciousness refers to people's understanding of social relations and social development, mainly manifested in philosophy, religion and humanities and social sciences. Existence, survival and development of individuals depend on social relations, especially relations of production and relations with other individuals. Every individual need to answer questions such as how to build social relations, how to deal with social relations, what's the general rules of society and how to survive and develop in a society. In fact, individual involvement in society is guided by personal values and social relations are coordinated by human's mind. Social institutions and structures are also created based on human's understanding of society. Understanding of social institutions and structures is, in a sense, understanding of social consciousness therein. It is why that social consciousness can reflect and regulate social relations and social institutions and structures. Especially since modern times, social institutions of a country are basically defined by law, operated by the government by using means of policy and administration. The theoretic basis for these arrangements is social consciousness. Economic, political and other social activities on the basis of social institutions and social structure also need to be guided by social consciousness. Of course, social consciousness varies by social class and era. It is condensed expression of different class interests and mentality.

Morality is a set of social norms governing people's consciousness and behavior. It is the embodiment of values and social consciousness, including but not limited to obligations, conscience, reputation and happiness. Other things related to morality include moral behavior, moral quality, moral evaluation, moral education and cultivation. To survive and develop, individuals will inevitably build relationships with others and the formation of moral values is inevitable. Although not binding on people, morality can restrict and regulate individual behavior mainly through public opinion and civil mechanisms. It is a social consciousness formed under specific historical conditions. It directly restricts the behavior of individuals almost in a ubiquitous fashion. 


\section{Consciousness of Economic and Political Practices in a Society is the Main Component of Culture}

Economic activity is the bedrock of culture. This proposition has become common sense but only conceptually. Few studies focus on in what specific way economic activity serve as bedrock of culture and how culture exists on the basis of economic activity. Some staunch supporters of empirical research and practicality believe that economic activity refers to material wealth production, exchange and distribution and is the allocation and combination of resources. No trace of culture can or should be found in economic activity. In other words, culture and economic activity are unrelated. Others argue that political activity is power games played by or conspiracy of politicians and culture, which is an abstract existence that influences politics by affecting political processes, and politics are separate existences.

What is origin of culture as consciousness about life and social relations? This paper argues that culture is neither a mystical existence nor external existence of society or human. Culture does not exist before human and society. It arises from reflections of human beings on their social existence and social practice. Economic and political activities are the basis and carrier of culture.

A. Economic and political activities are basic activities required for survival and development of human and also the most important means through which people create values. Consciousness of human beings naturally reflects their understanding of human economic and political practice. The major content of culture is economic and political activities of human which are basic subjects of human consciousness and give rise to and drive the development of culture.

B. Reflections of people on economic and political practice forms the basic content of culture.

First of all, people who have carried out economic activities in a certain historical period must ponder economic contradictions, economic rules and economic development mechanisms in these activities and develop relevant economic theories. Similarly, they also develop political theories based on their reflections on political contradictions and development rules. Of course, not everyone can directly gain rational knowledge about these contradictions, rules, development mechanisms, etc. which are studies systematically by specialists. However, the research of these specialists is not divorced from economic and political understandings of other individuals. In fact, their studies are based on economic and political understandings of other individuals which, together with their own thoughts, are summed up to form economic and political ideas which are used to provide guidance for economic and political activities of social institutions and individuals. These social ideas constitute an important part of culture and are embodied in values and morality.

Secondly, thoughts about motives of and interests in human activities form human values. Motives reflect human physiological and psychological needs. The endogenous drives to satisfy these needs motivate individuals to act. Motives are reflected throughout every human activity. They are the starting point and internal restrictions of human activities. However, human needs are not animal instincts. Human needs and motives triggered by them are limited by environment, especially social environment, as reflected in the fact that the formation and realization of motivations of economic and political activities and other motives is inseparable from economic and political activities and conditions. Interests are concrete outcomes of motives. Interests of people in economic and political activities include the possession of material wealth, the status gained in economic and political activities and the overall economic and political environment of society (systems, employment conditions, social security, etc.). Everyone will and should be aware of his/her own motives and interests. Awareness of economic and political motives and interests is the basic content of culture and reflected in human values.

Thirdly, thoughts about relationship between individuals in human activities constitute the moral content of culture. Economic and political activities are the basic activities required for the existence and continuation of human. They are also the basis for and the main form of social interaction. Interactions between individuals in economic and political activities give rise to various relations (including relations between individuals and relations between individuals and society) aligned to 
these activities. The handling and understanding of these relations constitute an important part of culture, mainly embodied in social morality, professional ethics and even family morality.

C. Culture exists in not only human mind but also in material fruits of human labor. The difference between material fruits from natural objects lies in the fact that material fruits contain the will and consciousness of human and are an embodiment of culture. In this way, economic and political processes are not only the production process of material fruits, but also the process of people using their own culture to transform and use materials.

\section{Culture Changes with Economic and Political Practices}

In terms of cultural contents, culture is a reflection of economic and political reality of a society. It is why cultures vary by country, ethnicity, era and region and demonstrate diversity.

Moreover, the culture of a society changes with its economic and political aspects. It is impossible to establish a culture that is not based on current political and economic fundamentals of the country or to copy foreign culture in its entirety or to restore national traditions in the whole. The propositions that Confucian culture, which was established based on thoughts of Confucius, Mencius, Xunzi, Xunzi, Zhongshu Dong, Yi Cheng, Hao Cheng, Xi Zhu, Jiuyuan Lu, Yangming Wang and other great Confucianism scholars, originated from the Chinese people's mind, and that culture was created by scholars who shut themselves up in their rooms ignore the internal links between culture, economy and politics. They are established based on the belief that culture is not a reflection of political and economic reality of a society. Culture defined in these propositions is unchangeable.

A part of culture indeed passed down from generation to generation in the form of traditions, but most contents of culture change with economic and political conditions. Even traditions are not maintained in their entirety but have been transformed to adapt to changing social conditions so they can still have practical value. Similarly, although the culture of a nation or an ethnic group is mainly embodied in reality, it is also constantly evolving.

This paper holds that culture restricts and regulates human activities and is a sign of a certain level of productivity and the reflection of values. Culture, once established on the basis of certain social reality, will constrain the activities of people of the same society or a similar society. It is because of the generality of culture that people from different cultures can communicate with each other, influence each other and learn from each other, in which process new cultures will be developed and productivity will be improved.

\section{Conclusion}

Culture encompasses values, social consciousness and moral values formed by people in their economic and political activities, and changes with economic and political activities. Studies of culture must examine culture in the context of economic and political facts, identify culture differences and commonality by studying the mentality and behavior of living people, including traditional culture that still practiced by modern society. We should develop our own culture by absorbing new cultural factors and drawing on things learned from culture exchanges.

\section{References}

[1] Edward Burnett Tylor, Primitive Culture, Cambridge University Press, 1871

[2] Bronisław Malinowski, A scientific theory of culture, The University of North Carolina press in Chapel Hill. 1944.

[3] Kroeber, A. L. and Kluckhohn, Clyde, Culture: A Critical Review of Concepts and Definitions. Vintage, 1963.

[4] Shuming Liang. The Essence of Chinese Culture. Xue Lin Press. Jun. 1987 
[5] Shuming Liang. Culture and Philosophy of Eastern and Western Worlds. Shanghai: Commercial Press. Jul. 1999

[6] Yijie Tang. Chinese Culture and Chinese Philosophy, SDX Joint Publishing Company. Dec. 1990

[7] Qizhi Zhang. Chinese Traditional Culture. Higher Education Press. Nov. 1994

[8] Yaonan Zhang, Ming Fang and Yijie Tang. Chinese Confucian Culture. Peking University Press. Jan. 2001

[9] Dainian Zhang and Keli Fang. Introduction to Chinese Culture. Beijing Normal University Press. Jan. 2008

[10] Yongji Liu. Modernization of Chinese Culture. Hebei University Press. May 1997

[11] Liwen Zhang et al. Traditional Culture and Modernization. China Renmin University Press. 1987 